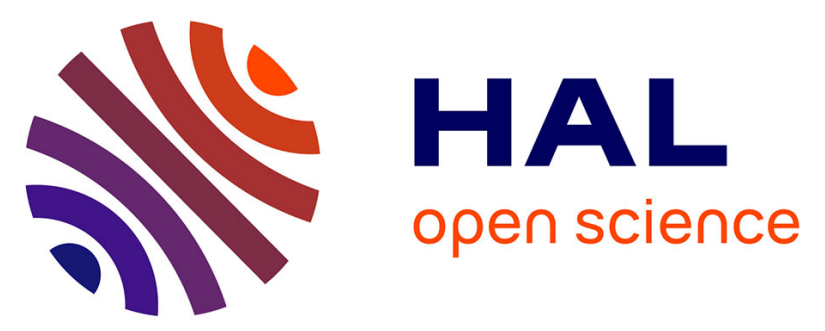

\title{
Irreplaceable area extends marine conservation hotspot off Tunisia: insights from GPS-tracking Scopoli's shearwaters from the largest seabird colony in the Mediterranean
}

David Grémillet, Clara Péron, Jean-Baptiste Pons, Ridha Ouni, Matthieu Authier, Mathieu Thévenet, Jérôme Fort

\section{To cite this version:}

David Grémillet, Clara Péron, Jean-Baptiste Pons, Ridha Ouni, Matthieu Authier, et al.. Irreplaceable area extends marine conservation hotspot off Tunisia: insights from GPS-tracking Scopoli's shearwaters from the largest seabird colony in the Mediterranean. Marine Biology, 2014, 161 (11), pp.26692680. 10.1007/s00227-014-2538-z . hal-01100281

\section{HAL Id: hal-01100281 \\ https://hal.science/hal-01100281}

Submitted on 20 Mar 2015

HAL is a multi-disciplinary open access archive for the deposit and dissemination of scientific research documents, whether they are published or not. The documents may come from teaching and research institutions in France or abroad, or from public or private research centers.
L'archive ouverte pluridisciplinaire $\mathbf{H A L}$, est destinée au dépôt et à la diffusion de documents scientifiques de niveau recherche, publiés ou non, émanant des établissements d'enseignement et de recherche français ou étrangers, des laboratoires publics ou privés. 
Irreplaceable area extends marine conservation hotspot off Tunisia - Insights from GPS-tracking endemic Scopoli's shearwaters from the largest seabird colony in the Mediterranean

David Grémillet, Clara Péron, Jean-Baptiste Pons, Ridha Ouni, Matthieu Authier, Mathieu Thévenet and Jérôme Fort

- $\quad$ David Grémillet, CEFE-CNRS, 1919 route de Mende 34293 Montpellier, France, and FitzPatrick Institute, DST/NRF Excellence Centre at the University of Cape Town, Rondebosch 7701, South Africa. Email: david.gremillet@ cefe.cnrs.fr

- $\quad$ Clara Péron, CEFE-CNRS, 1919 route de Mende 34293 Montpellier, France. Email : clara.peron@aad.gov.au. Present address: Institute for Marine and Antarctic Studies, University of Tasmania and Australian Antarctic Division, 203 Channel Highway, Kingston, Tasmania 7050, Australia.

- Jean-Baptiste Pons, Société d'Echantillonnage et d'Ingénierie Scientifique en Environnement, Le Bourg, 29259 Ile Molène, France. Email : seise.dir@gmail.com

- $\quad$ Ridha Ouni, Consultant en domaine de Biodiversité \& Ressource Naturelle. Sidi Thabet Cp 2020, Bp 23, Tunis, Tunisia. Email : elanion 2003@yahoo.fr

- Matthieu Authier, Observatoire PELAGIS, UMS3462, 5 allées de l'Océan, 17000 La Rochelle, France. Email: authier.matthieu@gmail.com

- Mathieu Thévenet, Conservatoire du Littoral, 3 rue Marcel Arnaud 13100 Aix en Provence, France. Email : albatros-PIM@conservatoire-du-littoral.fr

- Jérôme Fort, LIENSs-CNRS-Université La Rochelle, 2 rue Olympe de Gouges 17000 La Rochelle, France. Email: fort.jerome@gmail.com 


\begin{abstract}
Recent meta-analyses identified conservation hotpots at the scale of the Mediterranean, yet those may be crude by lack of detailed information about the spatial ecology of the species involved. Here we identify an irreplaceable marine area for $>95 \%$ of the world population of the Scopoli's shearwater (Calonectris diomedea), which is endemic to the Mediterranean and breeds on the island of Zembra off Tunis. To this end, we studied the three-dimensional at-sea movements of 50 breeding adults (over a total of 94 foraging trips) in 2012 and 2013, using GPS and Temperature-Depth recorders. Feathers were also collected on all birds to investigate their trophic status. Despite Zembra being the largest seabird colony in the Mediterranean (141,000 pairs), the per capita homerange of Scopoli's shearwaters foraging from this colony was not larger than that of birds from much smaller colonies, indicating highly beneficial feeding grounds in the Gulf of Tunis and off Cap Bon. Considering depleted Mediterranean small pelagic fish stocks, supposed to be Scopoli's shearwater prey base, we therefore speculate that birds may now also largely feed on zooplankton, something which is supported by our stable-isotopic analyses. Crucially, shearwater at-sea feeding and resting areas showed very little overlap with a conservation hotspot recently defined on the western side of the Gulf of Tunis using meta-analyses of species distributions relative to anthropogenic threats. We therefore propose a major extension to this conservation hotspot. Our study stresses the importance of detailed biotelemetry studies of marine megafauna movement ecology for refining large-scale conservation schemes such as MPA networks.
\end{abstract}




\section{Introduction}

The Mediterranean Sea is a biodiversity hotspot, threatened by the consequences of man-made environmental change, notably habitat destruction, overfishing, pollution and global warming (Blondel et al. 2010; Coll et al. 2010). A recent analysis identified a series of Mediterranean areas where high marine biodiversity concurs with intense cumulative threats; $<2 \%$ of the surface of these 'conservation hotspots' overlapped with existing conservation units, such as marine protected areas (Coll et al. 2012). This clearly shows that substantial efforts have to be made by national and international institutions to scale-up marine conservation. Meta-analyses such as those conducted by Coll et al. (2012) in the Mediterranean, and by Worm et al. (2005) and Halpern et al. (2008) at even larger scales are essential to attract the attention of the public and to raise the profile of global marine conservation. Yet they are not the only metric used to identify and designate priority areas for conservation; beyond indices of species occurrence and diversity, the irreplaceability of certain areas as habitats for specific threatened species is increasingly being recognised as a determinant selection criterion for the definition of priority conservation areas (Le Saout et al. 2013). Irreplaceable conservation areas are defined by crossing IUCN's world database of protected areas with IUCN's Red List of Threatened species, to generate an 'irreplaceability factor'. This factor is then used to rank the different conservation areas, and prioritise effective biodiversity conservation measures (Le Saout et al. 2013).

In the Mediterranean, Coll et al. (2012) identified a conservation hotspot off Tunisia, North Africa, on the basis of censuses for marine invertebrates, fish, turtles, marine mammals and seabirds. For seabirds, the authors used the list of breeding and non-breeding species that utilize the Mediterranean. For those species, they defined atsea ranges from expert-drawn distribution maps available in the Sea Around Us project database or in the literature. They performed this analysis once for the summer (most birds breeding), and once for the winter phase (most birds non-breeding). The year-round at-sea ranges of the seabird community were then compared to maps of anthropogenic threats, to identify the most critical conservation hotspots (Coll et al. 2012, and annexes therein).

Their analysis conducted at the scale of the Mediterranean and of the entire seabird community is extremely valuable, yet it could not possibly detail the spatial ecology of each of the species involved. The authors may therefore have missed some important information. Notably, their Tunisian marine conservation hotspot is in the vicinity of a coastal area which is potentially irreplaceable as a marine habitat for Scopoli's shearwaters (Calonectris diomedea), one of the four seabird species endemic to the Mediterranean. Indeed, this hotspot identified by Coll et al. (2012) is close to, but does not contain, the largest seabird colony in the entire 
Mediterranean, which is home to $>95 \%$ of the world population of Scopoli's shearwaters. This colony is situated on the island of Zembra in the north-eastern part of the Gulf of Tunis, Tunisia. Recent population censuses estimated that 141,000 pairs of Scopoli's shearwaters breed on Zembra Is. (Defos du Rau et al. 2012). Assuming two adults and one chick per pair, and a proportion of prospecting, non-breeding immatures corresponding to a third of the adult population, it is reasonable to estimate that Zembra Is. is the core of a sub-population in excess of half a million Scopoli's shearwaters during the breeding season. This species, formerly known as the Mediterranean form of Cory's shearwaters, has recently been split from the Atlantic form (Calonectris borealis), and is therefore identified as endemic to the Mediterranean and deserving special protection efforts (Sangster et al. 2012). Scopoli's shearwaters are mainly at threat from breeding habitat destruction and predation through rats and cats on land, where they nest in burrows (Ruffino et al. 2009), but also from competition with fisheries through food depletion and accidental killing by fishing gear at sea (Laneri et al. 2010). Zembra Is. has long been a military zone and is now a national park with planned management such as rat eradication. Up to now very little was known about the marine habitats of Scopoli's shearwaters from Zembra Is.. Studies conducted at other breeding locations and at-sea observations indicated that birds winter in the Atlantic (González-Solís et al. 2007; Péron and Grémillet 2013) and forage in the Mediterranean during the breeding season (Louzao et al. 2009; Cecere et al. 2013), but the exact extent of the latter foraging areas was so far unknown for most of the colonies. According to Cairns' Hinterland Model (Cairns 1989) colony-specific at-sea home ranges increase with colony size, and there is empirical evidence for this pattern (Lewis et al. 2001). Furthermore, the 'offshore diplomacy' model (Grémillet et al. 2004) posits that culturally-induced, colony-specific foraging asymetries may lead to mutually-exclusive foraging areas for neighbouring colonies (Masello et al. 2010, Thiébot et al. 2012), and Wakefield et al. (2013) suggested that this may be due to the use of public information. Along these lines, one may predict that, due to the very large size of the Zembra colony (two to three orders of magnitude larger than most shearwater colonies in the Mediterranean) birds may forage very widely, potentially using half of the surface of the Mediterranean and competitively excluding Scopoli's shearwaters from smaller breeding sites.

Since these patterns will have a strong impact on marine conservation in the Mediterranean, there was an urgent need for a detailed study of the foraging ecology of Zembra Scopoli's shearwaters, which we performed in 2012 and 2013 using electronic tools (GPS-recorders and Temperature-Depth-Recorders) and stable isotopic analyses of feather samples allowing an investigation of isotopic niche and trophic status. Specifically, we tested two interrelated hypotheses: (1) The per capita at-sea home range of Scopoli's shearwaters breeding on Zembra scales according to population size and is therefore far larger than for all other, smaller populations. To this end 
we compared the foraging range of Zembra birds with those of conspecifics from other sites which were tracked simultaneously using the same electronic devices (Péron and Grémillet 2014). (2) Irreplaceable at-sea habitat of Scopoli's shearwaters from Zembra goes far beyond the conservation hotspot identified by Coll et al. (2012) off Tunisia, and this potential marine protected area defined on the basis of the analysis by Coll et al. (2012) is too small to ensure the efficient protection of half a million shearwaters endemic to the Mediterranean. Overall, our data set allowed us to acquire substantial knowledge of Scopoli's shearwater at-sea ecology off Tunisia, which is essential for the design of forthcoming conservation plans at one of the 'hottest' Mediterranean marine conservation hotspots.

\section{Methods}

Data collection was performed at the Scopoli’s shearwater breeding colony of Zembra $\left(37^{\circ} 08^{`} \mathrm{~N}, 10^{\circ} 48^{`} \mathrm{E}\right)$ in the Eastern gulf of Tunis, Tunisia, under permits from the Agence de Protection et d'Aménagement du Littoral (APAL, Permit N 1864/12) and from the Direction des Services Vétérinaires (Permit N³4-369). All measurements were conducted during the chick-rearing phase; Scopoli’s shearwaters only raise one chick per breeding season, from July to early October. Sampling was conducted during this phase, which is the most energetically-demanding for the adults, and during which they are most sensitive to variation in regional food resources. Fieldwork took place between 6-18 August 2012 and from 20 August to 03 September 2013. Both field periods occurred during the chick-rearing period, which is protracted in shearwaters (3 months), and may last until October. Birds were therefore in mid chick-rearing in both cases, but we do not have more precise information because nests are too deep to catch/weigh chicks. Fieldwork consisted of catching breeding birds by hand at the entrance of their underground nests, weighing them (accuracy 10g), equipping them with GPSrecorders and Temperature-Depth-Recorders (TDR), and taking feather samples for stable isotope analyses. Birds were handled at night and all necessary precautions were taken to minimize handling stress: the bird was kept in the dark as much as possible and handling was performed silently in $<10 \mathrm{~min}$. We did not sex the birds studied, and assumed a balanced sex-ratio within our sample. Previous studies of Scopoli’s shearwaters based upon the same random capture technique of adult birds at the nest, which were subsequently sexed using molecular analysis of feather samples, showed that this assumption is reasonable (Péron and Grémillet 2014). 


\section{- $\quad$ Electronic equipment}

Seabird three-dimensional at-sea movements were tracked for periods of one to eight days using two types of electronic devices attached with black Tesa tape (to match plumage colour) to the lower back feathers (GPSrecorders) and to tail feathers (TDRs). All birds were equipped with GPS, and a subsample with GPS and TDR. The GPS-recorders were CatTraQTM wrapped in heat-shrink tubing for waterproofing (Catnip technologies, Hong Kong, China; 47x30x13 mm, 20g, corresponding to approx. 3\% of Scopoli's shearwater body mass). They provided GPS positions (approx. 5m positioning accuracy) every three minutes. The TDRs were G5 (CEFAS Technologies, Lowestoft, UK; $30 \mathrm{~mm}$ length, $7 \mathrm{~mm}$ diameter; $2.7 \mathrm{~g}$, corresponding to $0.4 \%$ of Scopoli's shearwater body mass). TDRs were set to record hydrostatic pressure every two seconds.

Three-dimensional at-sea movement data were used to (1) define the overall at-sea home-range of Scopoli's shearwaters from Zembra during the breeding season and compare it with smaller-sized colonies in France ; (2) Determine the foraging effort of the birds (in terms of foraging trip duration, foraging range, foraging speed); (3) Identify diving areas; (4) Identify areas within which flying birds actively foraged, rested at the water surface, or travelled (see details of filtering procedure below), and (5) Compare shearwater at-sea home-ranges, diving areas, foraging areas, resting and travelling areas with the conservation hotspot defined in Coll et al. (2012).

- Kernel density distribution

All spatial analyses and maps were implemented using R (version 2.13.0), with the packages 'Marmap' for bathymetry mapping (NOAA NGDC) and 'AdehabitatHR' for kernel density estimations (R Development Core Team 2011). Because individuals were tracked for different lengths of time (3-10 days), Kernel density distributions were generated for each individual bird (keeping all locations and multiple trips) and then averaged across individuals to estimate colony mean Kernel density distribution. Track locations were re-interpolated at regular time intervals ( $3 \mathrm{~min})$ to meet requirement of accurate density estimation. Kernels were generated using a fixed smoothing factor $\left(\mathrm{h}=0.04^{\circ}\right)$ and a fixed grid encompassing all trips (extent: $8.7^{\circ} \mathrm{E}-14^{\circ} \mathrm{E} / 32.6^{\circ} \mathrm{N}-38.4^{\circ} \mathrm{N}$, grid cell $=0.02^{\circ}$ ). The $\mathrm{h}$ factor was selected according to GPS accuracy (30m) and land locations avoidance. Kernel density distributions were plotted for each year using 90, 70, 50 and 25\% contours.

- $\quad$ Foraging trip characteristics and behavioural mapping

Foraging trips parameters were calculated from GPS positions after inspection of each individual trips to remove locations on land before or after a foraging trip or between two foraging trips. Maximum foraging range is the maximum distance reached during a foraging trip. Population average parameters and standard deviations are given in Table 1 for the two years of data collection. 
Dive profile analyses were performed using MultiTrace (Jensen Software Systems, Laboe, Germany), with a dive threshold value of $0.5 \mathrm{~m}$, corresponding to the resolution of the pressure sensor.

With respect to point (3) listed above, we matched GPS locations and diving information based on the exact time of each diving event. Since a bird could dive repeatedly during the time interval separating two GPS locations (3 min), a diving location was defined by a location where a bird dived at least once during this time period. However, it is known that shearwaters do not feed only while diving, but also while at the water surface (Zotier et al. 1999). We therefore also used Bayesian state-space modelling to infer behavioural modes from GPS track characteristics. To this end we adapted the triple-switch model of Morales et al. (2004), as detailed in Péron et al. (2013). Briefly, this method allows estimation of the sequence of states in animal tracking data based on characteristics of the track, where behaviour itself is not directly observable. Given the high accuracy of GPS fixes, we ignored measurement error. We hypothesized three 'hidden' behavioural modes: resting (small turning angle variance, small step length), foraging (large turning angle variance, intermediate step length), and travelling (small turning angle variance, large step length). We used posterior state probabilities to estimate activity budget and map bird behaviour.

- Home-range inter-colony comparison

We compared home-range size of Scopoli's shearwaters tracked in Zembra with those of 5 smaller size French colonies where Scopoli's shearwaters were tracked the same year (2012) during the chick rearing period (Frioul, $\mathrm{n}=15$ individuals, Riou, $\mathrm{n}=19$ individuals, Porquerolles, $\mathrm{n}=13$ individuals, Giraglia, $\mathrm{n}=30$ individuals and Lavezzi, n= 34 individuals, Péron and Grémillet 2014). Since the smallest sample size was 13 individuals tracked with GPS on Porquerolles Island, we performed a bootstrap analysis ( $\mathrm{n}=20$ runs) where 13 individuals were selected randomly on each colony to estimate mean Kernel density. Kernel densities were estimated on reinterpolated locations (regular time interval of $3 \mathrm{~min}$ ) that were projected using Lambert 93 geographic projection to allow estimation of home-range size in kilometres. We used a fixed smoothing factor $\left(\mathrm{h}=0.04^{\circ}\right)$ and a fixed grid encompassing all trips (extent: $3^{\circ} \mathrm{E}-14^{\circ} \mathrm{E} / 32^{\circ} \mathrm{N}-45^{\circ} \mathrm{N}$, grid cell $=0.02^{\circ}$ ). Home-range sizes were calculated on the basis of the $50 \%$ contour of each colony mean Kernel density distribution. Figure 4 describes the mean and standard error of home-range sizes estimated by bootstrap.

- $\quad$ Stable isotope analyses

Stable isotope analyses were performed on feather samples collected in 2012. Analyses closely followed the protocols detailed in Péron et al. (2013). Briefly, on each bird that was recaptured with an electronic device, we collected the tip $(1-2 \mathrm{~cm})$ of the first $(\mathrm{P} 1)$ and the tenth $(\mathrm{P} 10)$ primary feathers. These feathers were sampled 
according to the moulting sequence of Scopoli's shearwater: P1 is replaced during the breeding season while P10 grows during the non-breeding period (Ramos et al. 2009). Because feathers are metabolically inert once they have grown, their isotopic signatures provide information for the moulting period (Bearhop et al. 2002). Isotopic ratios measured on P1 and P10 therefore reflect the isotopic niche and trophic status of Scopoli's shearwater during the previous breeding and non-breeding periods, respectively. Prior to analysis, feathers were rinsed in a 2:1 chloroform:methanol solution, rinsed twice in a methanol solution, dried for $48 \mathrm{~h}$ at $60^{\circ} \mathrm{C}$ and homogenized with scissors. Analyses were performed at the Littoral Environnement et Sociétés institute (LIENSs, La Rochelle, France) on ca. 0,5 mg subsamples of material loaded into tin cups, using an elemental analyser (Thermo Fisher, Flash EA 1112) coupled in continuous flow mode to an isotope ratio mass spectrometer (Thermo Fisher, Delta V Advantage, Bremen, Germany). Stable isotope abundances were expressed in $\delta$ notation as the deviation from standards in parts per thousand (\%) according to the following equation: $\delta \mathrm{X}=$ [(Rsample/Rstandard) -1$] \times 1000$, where $\mathrm{X}$ is $13 \mathrm{C}$ or $15 \mathrm{~N}$ and $\mathrm{R}$ is the corresponding ratio $13 \mathrm{C} / 12 \mathrm{C}$ or $15 \mathrm{~N} / 14 \mathrm{~N}$. Standard values were Vienna-PeeDee Belemnite (VPDB) for C and atmospheric N2 (air) for N. The $\delta 15 \mathrm{~N}$ isotopic values reflect the relative trophic position of birds, while the $\delta 13 \mathrm{C}$ values mainly reflect the carbon source (i.e. habitat used by birds; Kelly 2000). From individual stable isotope signatures, standard ellipse areas corrected for small sample sizes (SEAc) were calculated to measure the isotopic niche width occupied by Scopoli's shearwater at both their breeding and non-breeding sites (Jackson et al. 2011). SEAc were calculated following Jackson et al. (2011) and using the package SIAR (Stable Isotope Analysis in R; Parnell et al. 2008) implemented in R software, version 3.0.2 (R Development Core Team 2011). Scopoli's shearwaters are known to spend their non-breeding season in the Atlantic Ocean (González-Solís et al. 2009; Péron and Grémillet 2013) and $\delta 13 \mathrm{C}$ isotope ratios measured on P10 reflect this specific habitat (see results; Ramos et al. 2009). However, a few birds showed different, intermediate $\mathrm{P} 10 \delta 13 \mathrm{C}$ ratios (see results) that suggest a moult of $\mathrm{P} 10$ in the Mediterranean (Ramos et al. 2009; Péron et al. 2013). Previous studies performed on the closely-related Cory’s shearwater suggested that some individuals can moult late in the non-breeding season when birds are travelling back to their breeding site and while already in the Mediterranean (Ramos et al. 2009). Similarly, it is likely that intermediate $\delta 13 \mathrm{C}$ isotopic values measured in this study on a few Scopoli's shearwaters don't reflect their isotopic niche and trophic status either at their non-breeding or at their breeding areas but rather in the Mediterranean at the end of the non-breeding season. Since we specifically aimed at investigating the trophic ecology of Scopoli's shearwaters at their breeding and non-breeding sites, these intermediate values were therefore not included in the statistical analyses. 


\section{Results}

- $\quad$ Spatial ecology

In 2012 we equipped 23 birds with GPS, of which 11 also carried a TDR. None of the devices fell off. Four of the birds could not be recaught, and we hence gathered complete GPS tracks for 19 birds and TDR recordings for 10 birds. Eight birds were tracked for one foraging trip, 8 for two trips, 2 for three trips and 1 for 4 trips, and we hence had information for a total of 34 complete trips. Similarly, in 2013 we equipped 37 birds with GPS, of which 13 carried TDRs. None of the devices fell off. We recaught 31 birds, yielding 31 GPS recordings and 10 TDR recordings. Nine birds were tracked for one foraging trip, 7 for two trips, 5 for three trips, 3 for four trips and 2 for five trips. Six trips were incomplete, and we hence had information for a total of 60 complete trips. A summary of foraging effort characteristics is provided in Table 1 and 2: birds stayed at sea for periods of two days on average, yet with a wide range of durations (1-8 days). All birds stayed within approx. $500 \mathrm{~km}$ of Zembra, with an average range of $90 \mathrm{~km}$ in 2012 and $105 \mathrm{~km}$ in 2013. Within this range, the total distance travelled covered an average of $400 \mathrm{~km}$ (maximum $1920 \mathrm{~km}$ ), which they travelled at average speeds of 8 to 9 $\mathrm{km} \cdot \mathrm{h}^{-1}$. Birds usually remained within 5 meters of the water surface (overall maximum dive depth of $10 \mathrm{~m}$, see Table 2).

Detailed spatial analysis allowed us to identify the areas used by the birds for travelling, for resting at the water surface, for active foraging (sinuous flight at low speed) and for diving. All such activities were performed close to Zembra, mainly within the Gulf of Tunis, off Cap Bon and the gulf of Hammamet, off the harbour of Kelibia (Fig. 1-3). This pattern was consistent across 2012-2013, with the exception of very few foraging trips towards Sicily and Libya (Fig. 1-3). Birds generally foraged at the surface, in waters $<200 \mathrm{~m}$ depth over the continental shelf (Fig. 1-2).

The at-sea homerange (50\% kernel contour) of Zembra Scopoli's shearwaters (141,000 pairs) was approximately $6,000 \mathrm{~km}^{2}$, which is three to ten times larger than the homeranges of Scopoli's shearwaters from French Mediterranean islands, which only harbour between 40-400 pairs. At-sea area per breeding pair was therefore two orders of magnitude smaller in Zembra shearwaters (approx. $0.04 \mathrm{~km}^{2}$ ) than for other colonies (between 2$16 \mathrm{~km}^{2}$; Fig. 4).

Further, the at-sea homerange of Scopoli's shearwaters from Zembra only very marginally overlapped with the conservation hotspot identified by Coll et al. (2012). This was the case for the kernel distribution of all recorded 
data (Fig. 1), as well as for foraging and resting positions (Fig. 2-3). Indeed, the Zembra homerange focused on the eastern part of the Gulf of Tunis, whereas the conservation hotspot of Coll and colleagues was centred on the western part of the Gulf of Tunis.

- Trophic status

When at their breeding (P1) and non-breeding (P10) sites, Scopoli's shearwaters occupied similar isotopic niche widths (SEAc; Tab. 3, Fig. 5), yet with some differences along the $\delta^{15} \mathrm{~N}$ and $\delta^{13} \mathrm{C}$ axes. During the breeding season, $\delta^{15} \mathrm{~N}$ values ranged over about $4 \%$ from 7.6 to $11.5 \%$, suggesting a wide range of consumed prey encompassing krill, fish larvae and small pelagic fish (Afán et al. 2014; Militão et al. 2012; Péron et al. 2013). The range of $\delta^{13} \mathrm{C}$ values was relatively narrow, ranging from -17.5 to $-16.0 \%$ (Tab. 3, Fig. 5). Conversely, at their non-breeding site, Scopoli's shearwaters exhibited a slightly wider range of $\delta^{13} \mathrm{C}$ values, in agreement with a larger diversity of areas and isotopic habitats occupied during this period (Péron and Grémillet 2013). $\delta^{15} \mathrm{~N}$ values ranged between 12.8 and 14.5\% suggesting a consistent trophic level across individuals (Tab. 3, Fig. 5).

\section{Discussion}

Our integrative study of the spatial and trophic ecology of Scopoli's shearwaters was conducted at the largest seabird colony in the Mediterranean, which is home to $>95 \%$ of all breeding individuals for this endemic species. Using this novel information collected on a total of 50 birds during the 2012-2013 breeding seasons, we examined our two hypotheses, and defined a marine area which is irreplaceable for the conservation of Scopoli's shearwaters at the species level.

\section{- Half a million seabirds neck-in-neck}

We reject our first hypothesis: the foraging range of Scopoli's shearwaters breeding on Zembra Is. does not increase according to population size. On the opposite, we found that homerange area per breeding pair was considerably smaller than for other, smaller populations which we studied using the same GPS-tracking technology (Fig. 4). This home range per pair was also smaller for Zembra Is. than for any of the Cory's Shearwater colonies studied by Ramos and colleagues (2013) off Northwest Africa. Conversely, pair-specific home range areas for other colonies in the western Mediterranean (Fig. 4) were within the range of those found by Ramos et al. (2013). Off Zembra island, the home range of Scopoli's shearwaters was centred on Cap Bon, at 
the eastern end of the Gulf of Tunis, and ranged over most of this gulf, as well as to the east of Cap Bon, to areas off the Gulf of Hammamet. Birds seldom ventured further west, or east, into the Gulf of Gabès or Libyan waters (Fig. 1-3). This is extremely surprising considering the very high productivity of the Gulf of Gabès, one order of magnitude higher than that of surrounding waters (Drira et al. 2010), which attracts high numbers of other marine predators such as sharks and turtles (Echwikhi et al. 2012, 2013), and is home to one of the major Mediterranean artisanal fisheries (Jabeur et al. 2000). Also, similar GPS tracking of Scopoli’s shearwaters from the island of Linosa, located in the middle of the strait of Sicily, showed that those birds do use waters South of Linosa extensively, and never ventured East towards Zembra (Cecere et al. 2013). There was thus a spatial segregation between birds foraging from the neighbouring colonies of Zembra and Linosa, with colony-specific, mutually exclusive foraging areas, which do not use their marine habitat at random within their maximum foraging range. This corresponds to the 'offshore diplomacy' model (sensu Grémillet et al. 2004), which predicts spatial segregation of pelagic seabirds foraging from neighbouring colonies (Wakefield et al. 2013). It is fascinating that the offshore diplomacy model holds in this system, considering that the Zembra breeding population of Scopoli's shearwaters is one order of magnitude larger than other colonies from the Strait of Sicily, with therefore an immense potential for 'invading' this entire marine region. Indeed, Cairns' hinterland model (Cairns 1989) predicts that the at-sea home range of seabird colonies scales according to colony size, a premise supported by a series of studies (Furness and Birkhead 1984; Lewis et al. 2001; Wakefield et al. 2013). Our study therefore represents a striking exception to this general pattern. In the absence of multidecadal data on shearwater population trends and pelagic fish availability in this part of the Mediterranean, one can only speculate upon the likely causes of this observation. For instance, this current state might be due to historically larger shearwater populations at other colonies in the Strait of Sicily, which may have competed with Zembra birds and excluded them from their hinterland situated eastwards of the Zembra colony. Similarly, the small shearwater breeding populations from the French Mediterranean coast shown on Figure 4 might be remnants of previously larger breeding colonies, which kept disproportionately large home ranges even after being decimated by rats and cats. Both options nonetheless seem unlikely, as recent seabird tracking data showed rapid adjustment of foraging effort and home ranges to population sizes (e.g. Lewis et al. 2006).

The extremely limited foraging range Scopoli's shearwaters from Zembra Is. also demonstrates that there are sufficient marine resources around Cap Bon to feed a seabird population > 500,000 individuals, as well as many other marine predators (seabirds, marine mammals, turtles, sharks and predatory fish). Scopoli's shearwaters are usually assumed to feed on small pelagic fish close to the sea surface (Zotier et al. 1999). Such small pelagic fish 
populations are considered as critically depleted in the Mediterranean, because of the combined effects of overfishing and climate change (Coll et al. 2008; GFCM 2013). One is therefore left wondering what the huge number of Scopoli's shearwaters which are foraging off Tunis during the breeding season are actually feeding upon. Fishery waste (discards and offal) are one option, but there is, to our knowledge, currently no information on the actual tonnage of waste discarded in Tunisian waters. There are 4,712 fishing vessels operating in this area (Zones GSA12 and 13; GFCM 2013) of which 26\% are equipped with hooks and lines susceptible to catch shearwaters. Waste volumes are probably substantial, yet a study is still required to estimate their use by Scopoli's shearwaters, as well as their attendance of liners, and the proportion of accidental shearwater mortality caught on fishing hooks.

Further, our stable isotopic analyses performed on shearwater feathers strongly suggest a wide trophic range, and hence a mixed diet of fish and zooplankton, when birds are breeding (Tab. 2, Fig. 5). Afán et al. (2014) investigated the trophic ecology of Scopoli’s shearwaters breeding on the northern coast of Morocco. Using stable isotope analyses on blood samples, they showed higher $\delta^{15} \mathrm{~N}$ values for this populations (12.2\%o), corresponding to a pelagic fish consumption (Afán et al. 2014). According to the equation proposed by Cherel et al. (2014) allowing correction and direct comparison of isotopic data obtained on seabird feather and blood samples, our $\delta^{15} \mathrm{~N}$ ratio of $9.9 \%$ measured on breeding bird feathers would correspond to a ratio of $9.3 \%$ for blood samples (see Cherel et al. 2014). Although this conversion should be considered with caution, it suggests that Scopoli's shearwaters breeding at Zembra feed at a lower trophic level than those from northern Morocco, and is in agreement with the hypothesis of a wide range of diet based on both zooplankton and fish. There is thus the possibility that shearwaters from Zembra Is. modify their diet, and feed less on small pelagic fish (e.g. sardines), and more on planktonic crustaceans or fish larvae. The broad trophic status of Zembra shearwaters is similar to that of other populations of the same species studied along the French Mediterranean coast (Péron and Grémillet 2014), indicating that this strategy occurs at the species' level, and that birds do not feed heavily on fishery waste. The Mediterranean marine megafauna is also increasingly feeding on gelatinous plankton whose populations are boosted by ocean warming (Cardona et al. 2012), and it remains to be investigated whether shearwaters may also benefit from this bounty. If Scopoli's shearwaters from Zembra are targeting zooplankton it is even more surprising that they do not exploit resources from the Gulf of Gabès, considering the extremely high primary and secondary productivity in this zone.

\section{- An irreplaceable marine area off Tunis}


We validate our second hypothesis: the at-sea habitat of Scopoli's shearwaters from Zembra does go far beyond the conservation hotspot identified by Coll et al. (2012) off Tunisia, and this potential marine protected area is far too small to ensure the efficient protection of habitat critically important for the conservation of this species endemic to the Mediterranean.

In this context, there are several ways to designate potential marine protected areas (MPAs). In many instances in the Mediterranean, MPAs were defined on the basis of remarkable benthic biodiversity e.g. the particular value of specific benthic habitats for species conservation. This is why all Mediterranean MPAs are coastal, with the exception of the Pelagos Sanctuary (between northern Corsica, the French Riviera and Italy) which was specifically designed to preserve pelagic habitats identified as critically important for large marine mammals (Notarbartolo-di-Sciara et al. 2008). 'Benthic-based' MPAs are sometimes also valuable for the conservation of pelagic species, as we recently demonstrated for Yelkouan shearwaters in the Western Mediterranean (Péron et al. 2013), yet seabirds often deserve special consideration with respect to MPA design (Pichegru et al. 2010). This is the approach followed by Coll et al. (2012), yet their analysis missed the specific relevance of the Gulf of Tunis for the conservation of Scopoli's shearwaters at the species level. This is because Coll et al. (2012) did not have access to information relative to the exact home range of Zembra shearwaters, in the absence of tracking data, and did not account for species abundance but occurrence only. Our study fills this gap, and therefore complements Coll et al. (2012); The conservation hotspot which we identified in this study does not question the area identified by Coll et al. (2012), but rather extends it over the entire Gulf of Tunis and the eastern side of Cap Bon. This extended hotspot, and potential MPA, may correspond to two designations: (1) an area irreplaceable (sensu Le Saout et al. 2013) for the maintenance of $95 \%$ of the entire population of Scopoli's shearwaters during the breeding season, and (2) a marine Important Bird Area (IBA).

Marine IBAs are defined according to a series of criteria (BirdLife International, 2010). Briefly, these relate to the conservation status of the species (which has to be on the IUCN Red List of threatened species), to the importance of the breeding site considered (which should hold $>1 \%$ of a biogeographic population), and to the use of at-sea areas, either in the vicinity of breeding colonies (as seaward extensions of protected areas), or further offshore (Lascelles et al. 2012). Marine IBAs may contain areas which are irreplaceable for the conservation of specific species, yet their selection criteria are far less stringent than those of an irreplaceable area. This is nicely illustrated by a recent study of Delord and colleagues (2014), which defined areas of importance for seabirds tracked from French southern territories. Their analysis included the critical endangered Amsterdam albatross (Diomedea amsterdamensis), which only breeds on Amsterdam Island in the Indian Ocean. 
Obviously the marine IBA which they defined using data for this species corresponds to an irreplaceable area. Conversely, Delord et al. (2014) also defined candidate marine IBAs using tracking data for king penguins (Aptenodytes patagonicus) breeding on Kerguelen. This species is of less conservation concern, and breeds on seven other archipelagos distributed across the subantarctic region. Their home range and candidate marine IBA as defined by Delord et al. (2014) is therefore not an irreplaceable area. This example illustrates the difference between marine IBAs and irreplaceable areas, and demonstrates that the two approaches are complementary. Yet, in the case of Scopoli's shearwaters breeding on Zembra Is., our analysis strongly suggests that the identified at-sea home range is more than a marine IBA, it is an irreplaceable conservation area with respect to this species endemic to the Mediterranean.

In conclusion, our study stresses the importance of performing detailed studies of the spatial ecology of specific marine species in the context of defining conservation hotspots deserving specific management, such as the designation of marine protected areas. This species-by-species approach might seem fastidious, yet in the case of the marine megafauna, including seabirds, recent miniaturisation of electronic technology, and the improvement of deployment techniques in e.g. large marine mammals, turtles, sharks and bony fish, are triggering a quantum leap in our capacity to explore the movement ecology of species at the population, and the meta-population levels (e.g. Frederiksen et al. 2012; Fort et al. 2012; Ramos et al. 2013).

Acknowledgments Fieldwork for this study was funded by the PIM initiative (Petites Iles de Méditerranée), while all electronic equipment was provided by the CEFE-CNRS Montpellier. Clara Péron was funded by the French agency for marine protected areas (AAMP) within the "Programme PACOMM, Natura2000 en mer". We are grateful to Ana Rodrigues for 'irreplaceable' advice, Marta Coll for providing us with the exact outline of the Tunisian conservation hotspot as defined in Coll et al. 2012, to Nory El Ksabi for preparing feathers samples prior to isotopic analyses, and to Owen McFarlane for checking our English. This work would have not been possible without the permission, the human and logistics support of the Tunisian Agence de Protection et d'Aménagement du Littoral (APAL), to whom we are most grateful.

\section{Ethical standards}

Data collection was performed under permits from the Agence de Protection et d'Aménagement du Littoral (APAL, Permit N 1864/12) and from the Direction des Services Vétérinaires (Permit N³4-369). 


\section{Conflict of interest}

The authors declare that they have no conflict of interest.

\section{References}

Afán I, Navarro J, Cardador L, Ramírez F, Kato A, Rodríguez B, Ropert-Coudert Y, Forero MG (2014) Foraging movements and habitat niche of two closely related seabirds breeding in sympatry. Mar Biol. doi: 10.1007/s00227-013-2368-4

Bearhop S, Waldron S, Votier SC, Furness RW (2002) Factors that influence assimilation rates and fractioning of nitrogen and carbon stable isotopes in avian blood and feathers. Physiol Biochem Zool 75: 451-458.

BirdLife International (2010) Marine Important Bird Areas toolkit: standardised techniques for identifying priority sites for the conservation of seabirds at sea. BirdLife International, Cambridge UK. Version 1.2: February 2011

Blondel J, Aronson J, Bodiou J, Boeuf G (2010) The Mediterranean region: biological diversity through time and space. Oxford University Press, Oxford.

Cardona L, Álvarez de Quevedo I, Borrell A, Aguilar A (2012) Massive Consumption of Gelatinous Plankton by Mediterranean Apex Predators. PLoS ONE 7(3): e31329. doi:10.1371/journal.pone.0031329

Cecere JG, Catoni C, Maggini I, Imperio S, Gaibani G (2013) Movement patterns and habitat use during incubation and chick-rearing of Cory's shearwaters (Calonectris diomedea diomedea) (Aves: Vertebrata) from Central Mediterranean: influence of seascape and breeding stage. Ital J Zool 80: 82-89. doi: $10.1080 / 11250003.2012 .710654$

Cherel Y, Jaquemet S, Maglio A, Jaeger A (2014) Differences in $\delta 13 \mathrm{C}$ and $\delta 15 \mathrm{~N}$ values between feathers and blood of seabirds chicks : implications for non-invasive isotopic investigations. Mar Biol 161: 229-237. doi: 10.1007/s00227-013-2314-5

Cairns DK (1989) The regulation of seabird colony size — a Hinterland model. Am Nat 134: 141-146. doi:10.1086/284970

Coll M, Lotze HK, Romanuk TN (2008) Structural degradation in Mediterranean sea food webs: testing ecological hypotheses using stochastic and mass-balance modelling. Ecosystems 11: 939-960. doi: 10.1007/s10021-008-9171-y 
Coll M, Piroddi C, Steenbeek J, Kaschner K, Ben Rais Lasram F, et al. (2010) The Biodiversity of the Mediterranean Sea: Estimates, Patterns, and Threats. PLoS ONE 5(8): e11842. doi:10.1371/journal.pone.0011842

Coll M, Piroddi C, Albouy C, Ben Rais Lasram F, Cheung WWL, Christensen V, et al. (2012) The Mediterranean under siege: spatial overlap between marine biodiversity, cumulative threats and marine reserves. Glob Ecol Biogeo 21: 465-480. doi: 10.1111/j.1466-8238.2011.00697.x

Defos du Rau P, Bourgeois K, Ruffino L, Dromzée S, Ouni R, Abiadh A, et al. (2012) New assessment of the world's largest colony of Scopoli's Shearwater Calonectris diomedea. Proceedings of the $13^{\text {th }}$ Medmaravis pan-Mediterranean Symposium. P. 26-28

Delord K, Barbraud C, Bost CA, Deceuninck B, Lefebvre T, Lutz R, Micol T, Phillips RA, Trathan PN, Weimerskirch H (2014) Areas of importance for seabirds tracked from French southern territories, and recommendations for conservation. Mar Pol 48: 1-13. (DOI): 10.1016/j.marpol.2014.02.019.

Drira, Z, Belhassen M, Ayadi H, Hamza A, Zarrad R, Bouïn A, Aleya L (2010) Copepod community structure related to environmental factors from a summer cruise in the Gulf of Gabès (Tunisia, eastern Mediterranean Sea). J Mar Biol Assoc UK 90: 145-157. doi: http://dx.doi.org/10.1017/S0025315409990403

Echwikhi K, Jribi I, Bradai MN, Bouaïn (2012) Overview of loggerhead turtles coastal nets interactions in the Meditteranean Sea. Aquat Cons 22: 827-835. doi: 10.1002/aqc.2270

Echwikhi K, Saidi B, Bradai MN, Bouaïn A (2013) Preliminary data on elasmobranch gillnet fishery in the Gulf of Gabès, Tunisia. J Appl Icht 29: 1080-1085. doi: 10.1111/jai.12022

Fort J, Pettex E, Tremblay Y, Lorentsen S-H, Garthe S, Votier S, Pons J-B, Siorat F, Furness RW, Grecian JW, Bearhop S, Montevecchi WA, Grémillet D (2012). Meta-population evidence of oriented chain migration in northern gannets (Morus bassanus). Front Ecol Env 10: 237-242. doi: http://dx.doi.org/10.1890/110194

Frederiksen F, Moe B, Daunt F, Phillips RA, Barrett RT, Bogdanova MI, Boulinier T et al. (2012) Multicolony tracking reveals the winter distribution of a pelagic seabird on an ocean basin scale. Div Distr 18: 530-542. doi: $10.1111 / \mathrm{j} .1472-4642.2011 .00864 . x$

Furness RW, Birkhead TR (1984) Seabird colony distributions suggest competition for food during the breeding season. Nature 311: 655-656. doi:10.1038/311655a0

GFCM (General Fisheries Commission for the Mediterranean) 2013. Report of the fifteenth session of the Scientific Advisory Committee. Rome, 8-11 April 2013. FAO Fisheries and Aquaculture Report No. 1042. $96 \mathrm{pp}$ 
González-Solís J, Croxall JP, Oro D, Ruiz X (2007) Trans-equatorial migration and mixing in the wintering areas of a pelagic seabird. Front Ecol Env 5: 297-301. doi: http://dx.doi.org/10.1890/15409295(2007)5[297:TMAMIT]2.0.CO;2

Grémillet D, Dell'Omo G, Ryan PG, Peters G, Ropert-Coudert Y, Weeks S (2004) Offshore diplomacy, or how seabirds mitigate intra-specific competition : a case study based on GPS tracking of cape gannets from neighbouring breeding sites. Mar Ecol Progr Ser 268: 265-279.

Halpern BS, Walbridge S, Selkoe KA, Kappel CV, Michelli F, D’Agrosa C et al. (2008) A global map of human impact on marine ecosystems. Science 319: 948-952. doi: 10.1126/science.1149345

Jabeur C, Gobert B, Missaoui H (2000) Typologie de la flotilla de pêche côtière dans le golfe de Gabès (Tunisie). Aquat Liv Res 13 : 421-428. doi: http://dx.doi.org/10.1016/S0990-7440(00)01069-X

Jackson AL, Inger R, Parnell AC, Bearhop S (2011) Comparing isotopic niche widths among and within communities: SIBER - Stable Isotope Bayesian Ellipses in R. J Anim Ecol 80: 595-602. doi: 10.1111/j.1365-2656.2011.01806.x

Kelly JF (2000) Stable isotopes of carbon and nitrogen in the study of avian and mammalian trophic ecology. Can J Zool 78: 1-27. doi: 10.1139/z99-165

Laneri K, Louzao M, Martinez-Abran A, Arcos J, Belda E, Guallart J, Sánchez A, Giménez M, Maestre R, Oro, D (2010) Trawling regime influences longline seabird bycatch in the mediterranean: new insights from a small-scale fishery. Mar Ecol Progr Ser 420:241-252. doi: 10.3354/meps08847

Lascelles, B.G., Langham G.M, Ronconi R.A., Reid J.B. (2012) From hotspots to site protection: identifying marine protected areas for seabirds around the globe. Biological Conservation 156: 5-14.

Le Saout S, Hoffmann M, Shi Y, Hughes A, Bernard C, Brooks TM, Bertzky B, Butchart SHM, Stuart SN, Badman T, Rodrigues ASL (2013) Protected areas and effective biodiversity conservation. Science 342: 803-805. doi: 10.1126/science.1239268

Lewis S, Sherratt TN, Hamer KC, Wanless S (2001) Evidence of intra-specific competition for food in a pelagic seabird. Nature 412: 816-819. doi :10.1038/35090566

Lewis S, Grémillet D, Daunt F, Ryan PG, Crawford RJM, Wanless S (2006) Using behavioural variables to identify proximate causes of population change in a seabird. Oecologia 147: 606-614. DOI $10.1007 / \mathrm{s} 00442-005-0321-\mathrm{z}$ 
Louzao M, Bécares J, Rodríguez B, Hyrenbach KD, Ruiz A, Arcos JM (2009) Combining vessel-based surveys and tracking data to identify key marine areas for seabirds. Mar Ecol Progr Ser 391: 183-197. doi: 10.3354/meps08124

Masello, JF, Mundry R, Poisbleau M, Demongin L, Voigt CC, Wikelski M, Quillfeldt P (2010) Diving seabirds share foraging space and time within and among species. Ecosphere 1: article 19. doi/pdf/10.1890/ES1000103.1

Militão T, Bourgeois K, Roscales JL, González-Solís J (2012) Individual migratory patterns of two threatened seabirds revealed using stable isotope and geolocation analyses. Div and Distr 19: 317-329. doi: 10.1111/j.1472-4642.2012.00916.x

Morales JM, Haydon DT, Frair J, Holsinger KE, Fryxell JM (2004) Extracting more out of relocation data : building movement models as mixtures of random walks. Ecology 85: 2436-2445. doi: http://dx.doi.org/10.1890/03-0269

NOAA National Geophysical Data Center. GEODAS Grid Translator - Design a grid. URL http://www.ngdc.noaa.gov/mgg/gdas/gd_designagrid.html

Notarbartolo-di-Sciara G, Agardy T, Hyrenbach DK, Scovazzi T, Van Klaveren P (2008) The Pelagos sanctuary for Mediterranean marine mammals. Aquat Cons 18: 367-391. doi: 10.1002/aqc.855

Parnell A, Inger R, Bearhop S, Jackson AL (2008) SIAR: stable isotope analysis in R. http://cran.rproject.org/web/packages/siar/

Péron C, Grémillet D, Prudor A, Pettex E, Saraux C, Soriano-Redondo A, Authier M, Fort J (2013) Importance of coastal Marine Protected Areas for the conservation of pelagic seabirds: The case of Vulnerable yelkouan shearwaters in the Mediterranean Sea. Biol Cons 168: 210-221. doi: http://dx.doi.org/10.1016/j.biocon.2013.09.006

Péron C, Grémillet D (2013) Tracking through Life Stages: Adult, Immature and Juvenile Autumn Migration in a Long-Lived Seabird. PLoS ONE 8(8): e72713. doi:10.1371/journal.pone.0072713

Péron C, Grémillet D (2014) Habitats marins des puffins de France métropolitaine. Agence des Aires Marines Protégées.

Pichegru L, Grémillet D, Crawford RJM, Ryan PG (2010) Marine no-take zone rapidly benefits endangered penguin. Biol Let 6: 498-501. doi: 10.1098/rsbl.2009.0913

Ramos R, González-Solís J, Forero MG, Moreno R, Gómez-Díaz E, Ruiz X, Hobson KA (2009) The influence of breeding colony and sex on mercury, selenium and lead levels and carbon and nitrogen isotope 
signatures in summer and winter feathers of Calonectris shearwaters. Oecologia 159:345-354. doi: $10.1007 / \mathrm{s} 00442-008-1215-7$

Ramos R, Granadeiro JP, Rodríguez B, Navarro J, Paiva VH, Bécares J, Reyes-González JM, Fagundes I, Ruiz A, Arcos P, González -Solís J, Catry P (2013) Meta-population feeding grounds of Cory’s shearwaters in the subtropical Atlantic ocean: implications for the definition of Marine Protected Areas based on tracking studies. Div and Distr 19: 1284-1298. doi: 10.1111/ddi.12088

Ruffino L, Bourgeois K, Vidal E, Duhem C, Paracuellos M, Escribano F, Sposimo P, Baccetti N, Pascal M, Oro D (2009) Invasive rats and seabirds after 2,000 years of an unwanted coexistence on mediterranean islands. Biol Inv 11:1631-1651. doi: 10.1007/s10530-008-9394-Z

Sangster G, Collinson JM, Crochet PA, Knox AG, Parkin DT et al. (2012) Taxonomic recommendations for British birds: eighth report. Ibis 154: 883. doi: 10.1111/j.1474-919X.2012.01273.x

Thiébot JB, Cherel Y, Trathan PN, Bost CA (2012) Coexistence of oceanic predators on wintering areas explained by population-scale foraging segregation in space or time. Ecology 93: 122-130. http://dx.doi.org/10.1890/11-0385.1

Wakefield ED, Bodey TW, Bearhop S, Blackburn J, Colhoun K, Davies R, et al. (2013) Space partitioning without territoriality in gannets. Science 341:68-70. doi: 10.1126/science.1236077

Worm B, Sandow M, Oschlies A, Lotze HK, Myers RA (2005) Global patterns of predator diversity in the open oceans. Science 309: 1365-1369. doi: 10.1126/science.1113399

Zotier R, Bretagnolle V, Thibault J-C. (1999) Biogeography of the marine birds of a confined sea, the Mediterranean. J Biogeo 26:297-313. 
Table 1 Foraging trip characteristics of birds tracked by GPS in 2012 and 2013. Averages are provided \pm standard deviation, followed by the range.

\begin{tabular}{|c|c|c|c|c|}
\hline Year & $\begin{array}{c}\text { Maximum } \\
\text { Foraging range } \\
\text { (km) }\end{array}$ & $\begin{array}{l}\text { Total distance } \\
\text { travelled }(\mathrm{km})\end{array}$ & $\begin{array}{c}\text { Travelling speed } \\
\left(\mathrm{km} \mathrm{h}^{-1}\right)\end{array}$ & $\begin{array}{c}\text { Trip duration } \\
\text { (days) }\end{array}$ \\
\hline $\begin{array}{l}2012 \\
n=34\end{array}$ & $\begin{array}{l}89.7 \pm 115.2 \\
{[9.6-513.8]}\end{array}$ & $\begin{array}{l}367.6 \pm 447.7 \\
{[62.5-1883.9]}\end{array}$ & $\begin{array}{l}7.6 \pm 2.5 \\
{[3.1-13.5]}\end{array}$ & $\begin{array}{l}1.8 \pm 1.9 \\
{[0.7-7.9]}\end{array}$ \\
\hline $\begin{array}{l}2013 \\
n=60\end{array}$ & $\begin{array}{l}104.8 \pm 91.8 \\
{[10.0-460.9]}\end{array}$ & $\begin{array}{l}441.8 \pm 393.0 \\
{[51.7-1919.7]}\end{array}$ & $\begin{array}{l}9.2 \pm 3.1 \\
{[2.2-19.1]}\end{array}$ & $\begin{array}{l}2.0 \pm 1.6 \\
{[0.7-7.0]}\end{array}$ \\
\hline
\end{tabular}


Table 2 Diving behaviour of birds equipped with TDR in 2012 and 2013. Averages are provided \pm standard deviation, followed by the range.

\begin{tabular}{|c|c|c|c|}
\hline Year & $\begin{array}{c}\text { Number of dives } \\
\text { per trip }\end{array}$ & Dive duration (s) & Dive depth (m) \\
\hline 2012 & $9 \pm 8$ & $8.1 \pm 2.6$ & $1.9 \pm 1.3$ \\
$\mathrm{n}=10$ & {$[1-27]$} & {$[5.6-14.0]$} & {$[0.7-5.4]$} \\
\hline 2013 & $49 \pm 47$ & $7.8 \pm 1.4$ & $1.7 \pm 0.8$ \\
$\mathrm{n}=10$ & {$[8-159]$} & {$[5.7-9.4]$} & {$[0.6-3.5]$} \\
\hline
\end{tabular}


Table 3 Stable isotope values of nitrogen and carbon in feathers of Scopoli's shearwaters sampled during the 2012 breeding season. Standard ellipse areas (SEAc) represent a measure of isotopic niche widths for each batch of feathers and each season. ${ }^{*} \mathrm{P} 10$ results only include feathers for which $\delta^{13} \mathrm{C}$ values reflect a moult at the nonbreeding area (see Methods for details).

\begin{tabular}{|c|c|c|c|c|c|c|c|}
\hline \multirow[b]{2}{*}{ Feather } & \multirow[b]{2}{*}{ Moult season } & \multirow[b]{2}{*}{$n$} & \multicolumn{2}{|c|}{$\delta^{15} \mathrm{~N}(\% 0)$} & \multicolumn{2}{|c|}{$\delta^{13} \mathrm{C}(\%)$} & \multirow[t]{2}{*}{ SEAc } \\
\hline & & & Mean \pm SD & Range & Mean \pm SD & Range & \\
\hline $\mathrm{P} 1$ & Breeding & 18 & $9.9 \pm 1.0$ & 7.6 to 11.5 & $-17.1 \pm 0.3$ & -17.5 to -16.0 & 1.11 \\
\hline $\mathrm{P} 10^{*}$ & Non-breeding & 12 & $13.8 \pm 0.5$ & 12.8 to 14.5 & $-14.4 \pm 0.6$ & -15.4 to -13.4 & 0.88 \\
\hline
\end{tabular}



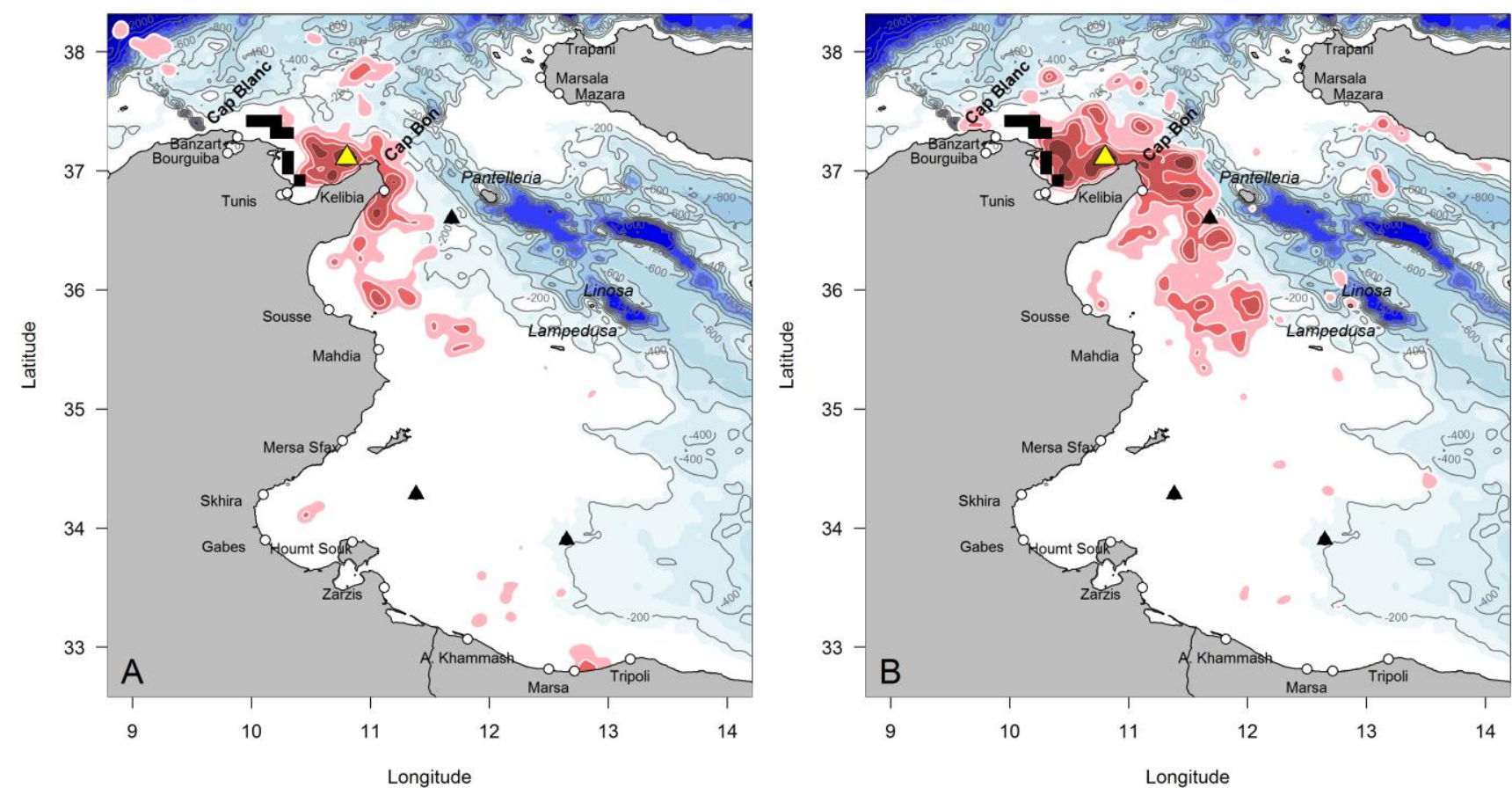

Fig. 1 Kernel density distributions (90, 70, 50 and 25\%: pink to red) of GPS positions (multiple track per individual) recorded for Scopoli's shearwaters from the Zembra breeding colony (yellow triangle) when at-sea (A: 19 birds in 2012; B: 31 birds in 2013). White to blue contours indicate bathymetry. Areas identified as belonging the Tunisian conservation hotspot are indicated as black rectangles (adapted from Coll et al. 2012, Fig 5d). The main harbours are indicated by open circles, and oil terminals by black triangles. 

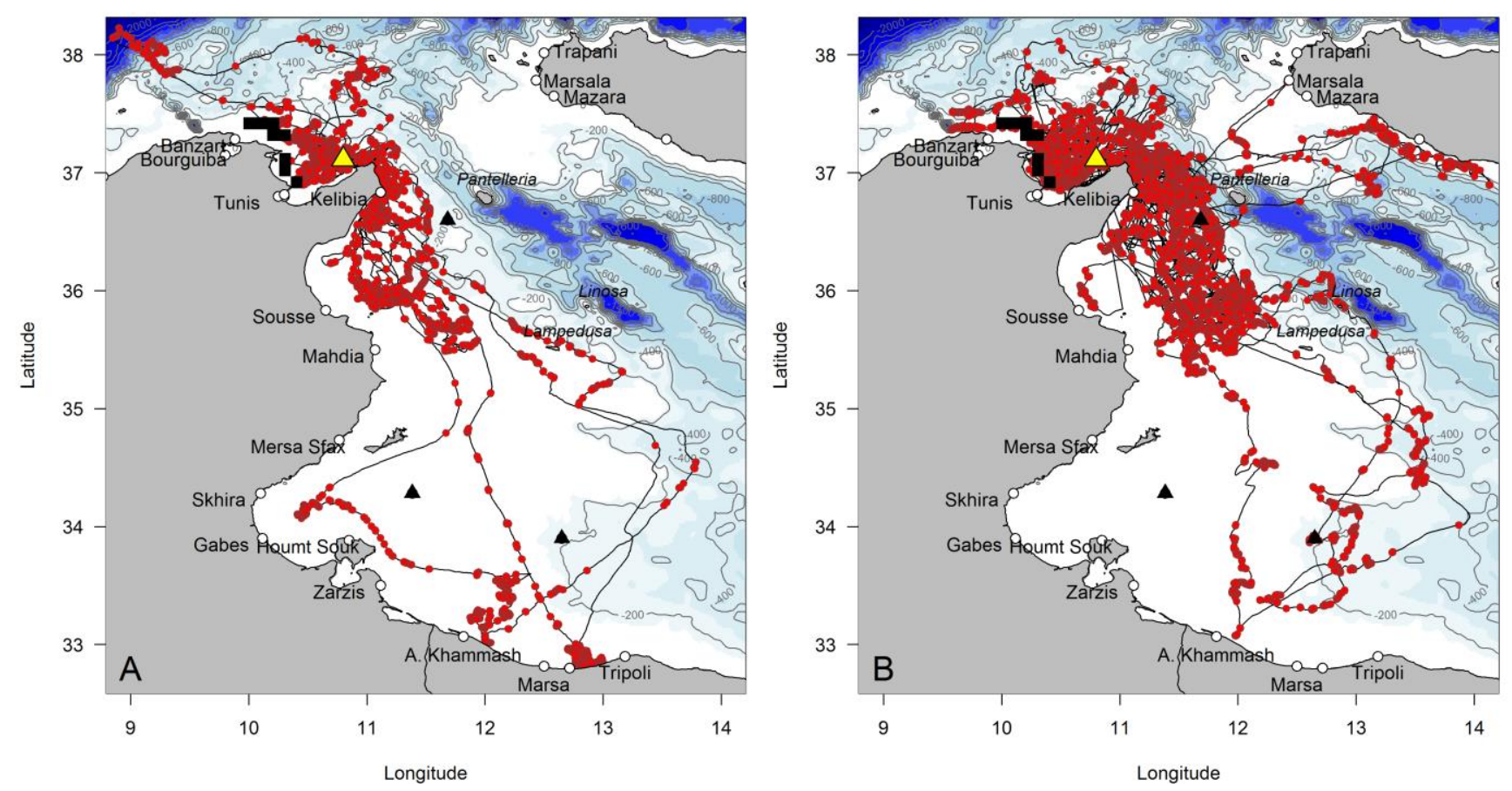

Fig. 2 Foraging positions (red dots) identified by state-space filtering (see methods), along the GPS tracks of Scopoli's shearwaters from the Zembra breeding colony (yellow triangle) when at-sea (A: 19 birds performing 35 trips in 2012; B: 31 birds performing 59 trips in 2013). White to blue contours indicate bathymetry. Areas identified as belonging the Tunisian conservation hotspot are indicated as black rectangles (adapted from Coll et al. 2012, Fig. 5d). The main harbours are indicated by open circles, and oil terminals by black triangles. 

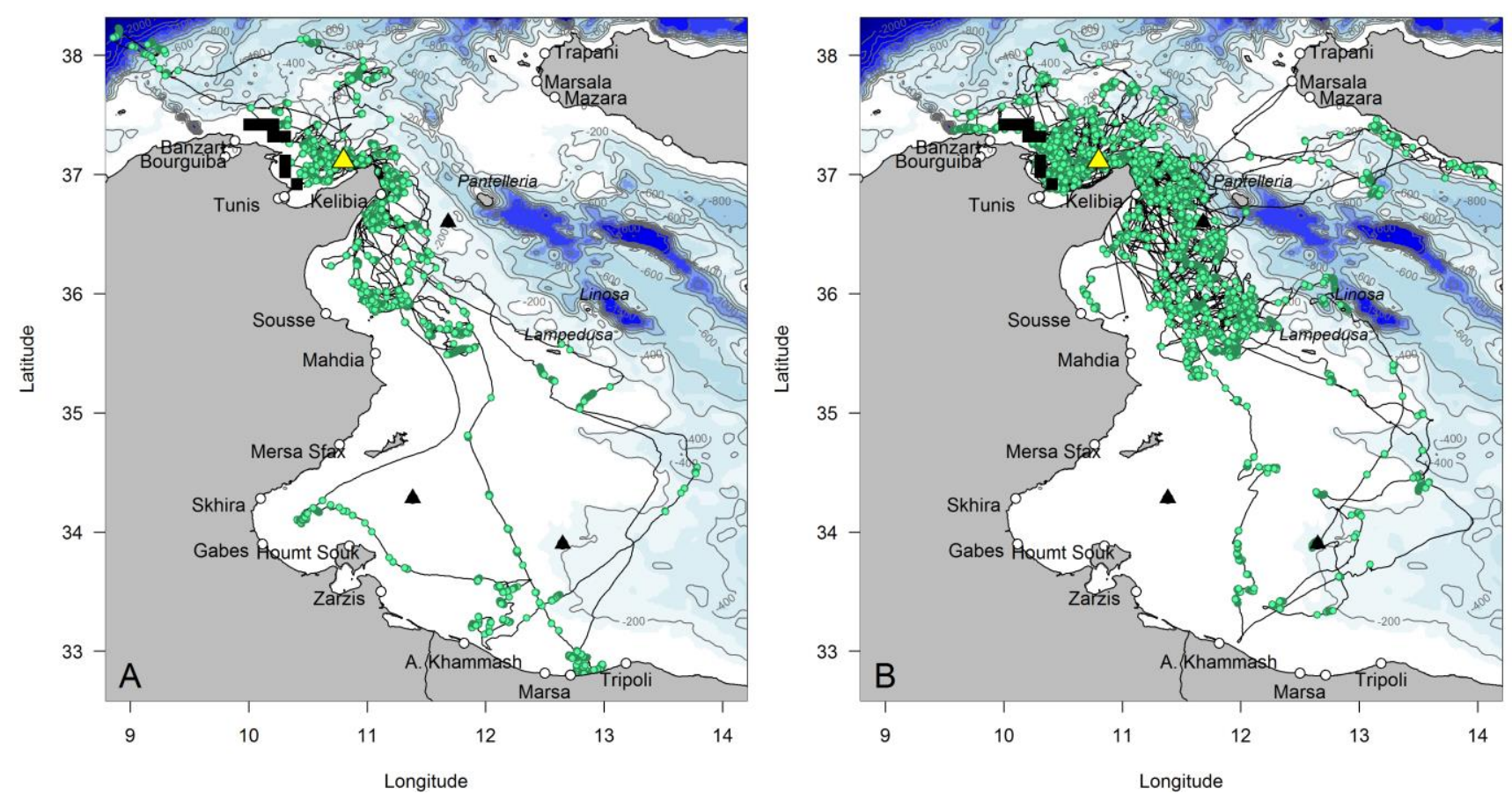

Fig. 3 Resting positions (green dots) identified by state-space filtering (see methods), along the GPS tracks of Scopoli's shearwaters from the Zembra breeding colony (yellow triangle) when at-sea (A: 19 birds performing 35 trips in 2012; B: 31 birds performing 59 trips in 2013). White to blue contours indicate bathymetry. Areas identified as belonging the Tunisian conservation hotspot are indicated as black rectangles (adapted from Coll et al. 2012, Fig. 5d). The main harbours are indicated by open circles, and oil terminals by black triangles. 


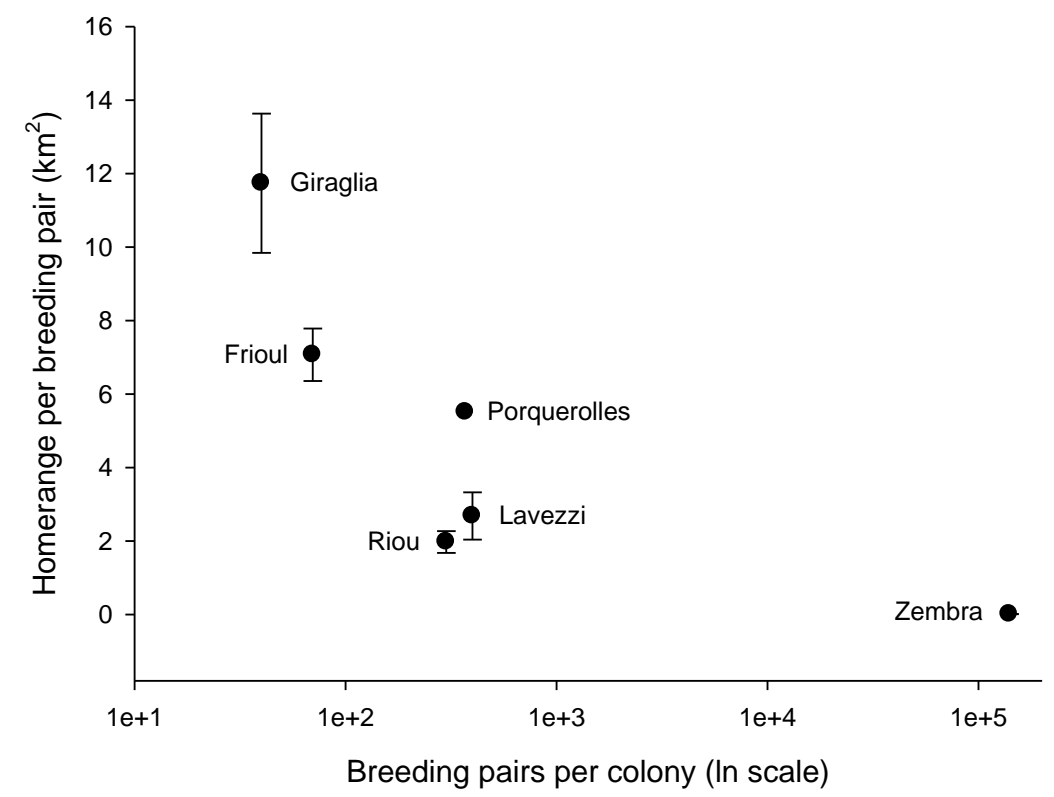

Fig. 4 Relationship between home-range per breeding pair $\left(\mathrm{km}^{2}\right)$ and colony size (pairs) for Scopoli's shearwaters in the Western Mediterranean. Colony-specific home-ranges were calculated as the surface of 50\% kernel density distributions. Confidence intervals were generated by boostrapping (see methods for details). There are no confidence intervals for the Porquerolles site since this was the colony with the minimum number of birds studied $(n=13)$, and the confidence interval for Zembra is too small to be visible. All data were collected during the 2012 chick-rearing phase. Colony size ranges between 40 pairs (Giraglia) and 141,000 pairs (Zembra). 


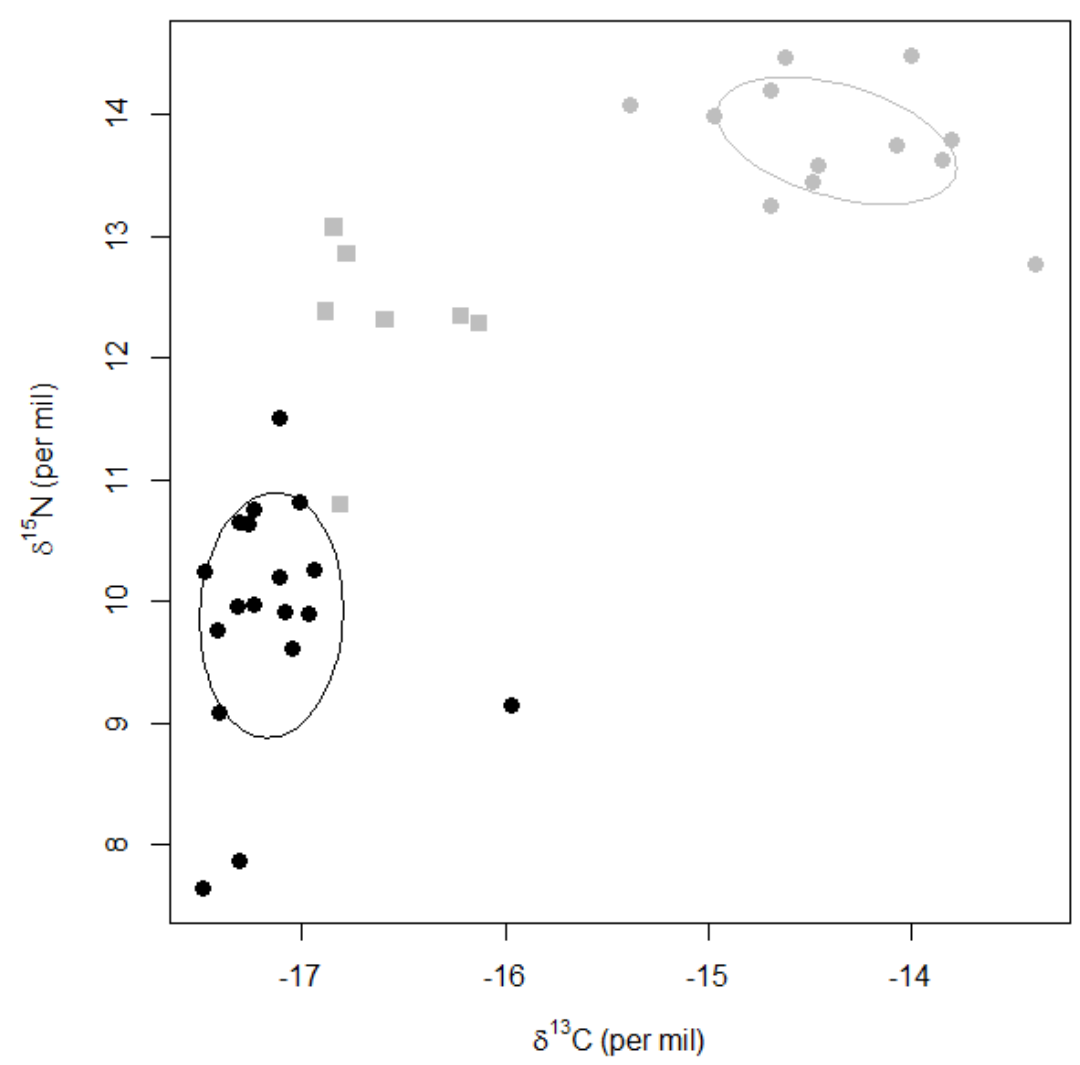

Fig. 5 Individual stable carbon and nitrogen isotope values of Scopoli's shearwaters measured on P1 (blackfilled circles) and P10 (grey-filled symbols) feathers. P10 feathers were divided in two groups: P10 moulted at the non-breeding sites in the Atlantic Ocean (Péron and Grémillet 2013) and characterized by enriched $\delta 13 \mathrm{C}$ ratios (grey-filled circles; Militão et al. 2012), and P10 showing intermediate $\delta 13 \mathrm{C}$ ratios (grey-filled squares) most likely molted late in the non-breeding season when birds were travelling back to their breeding site (see Methods for details). Standard ellipse areas (SEAc) are represented for P1 and P10 molted in the Atlantic Ocean. 